\title{
A armadilha da liberalização: Por que a América Latina parou nos anos 1980, enquanto o Leste da Ásia continuou a crescer?
}

\author{
The liberalization trap: Why did Latin America fall behind \\ in the 1980s while East Asia continue to grow?
}

LUIZ CARLOS BRESSER-PEREIRA*

\begin{abstract}
RESUMO: Nos anos 80, enquanto os países do Leste Asiático continuaram a crescer, os países latino-americanos pararam e, desde então, estão ficando para trás. A causa não foi a "armadilha da renda média”, mas a "armadilha da liberalização". Diferentemente do leste asiático, os países latino-americanos sofrem da doença holandesa, mas conseguiram se industrializar porque usaram altas tarifas de importação de produtos manufaturados para neutralizar essa supervalorização da taxa de câmbio a longo prazo. Na década de 1980, no entanto, a liberalização do comércio desmontou esse mecanismo. A consequente desvantagem competitiva produziu desindustrialização e baixo crescimento.

PALAVRAS-CHAVE: Armadilha de renda média; armadilha de liberalização comercial e financeira; doença holandesa.
\end{abstract}

ABSTRACT: In the 1980s, while the East Asian countries continued to grow, the Latin American countries stopped, and since then are falling behind. The cause was not the "middleincome trap", but the "liberalization trap". Differently from the East Asian, the Latin American countries suffer the Dutch Disease, but were able to industrialize because they used high import tariffs on manufactured goods to neutralize this long-term overvaluation of the exchange rate. In the 1980s, however, trade liberalization dismounted this mechanism. The ensuing competitive disadvantage produced deindustrialization and low growth.

KEYWORDS: Middle-income trap; trade and financial liberalization trap; Dutch Disease. JEL Classification: O11; O24.

O sucesso da estratégia voltada para as exportações de bens manufaturados e o equilíbrio orçamentário no Leste da Ásia têm há muito servido de modelo de sucesso para economias em industrialização. Em contrapartida, a liberalização

\footnotetext{
* Professor emérito da Fundação Getulio Vargas - FGV, São Paulo/SP, Brasil. E-mail: bresserpereira@gmail. com. Orcid https://orcid.org/0000-0001-8679-0557. Submetido: 23/maio/2019 Aprovado; 15/julho/2019.
} 
comercial não levou os países da América Latina a retomar o desenvolvimento econômico quase paralisado desde os anos 1980. Este fato é geralmente atribuído à "armadilha da renda média", mas neste caso por que os países do Leste da Asiático não foram vítimas da mesma armadilha? Enquanto no Leste da Ásia os países já eram exportadores de bens manufaturados e relativamente abertos, na América Latina a liberalização comercial significou a desmontagem dos mecanismos que neutralizavam a sua doença holandesa e uma grande desvantagem competitiva para as boas empresas industriais da região.

Os estudos sobre a armadilha da renda média datam do início dos anos 2010. Diversos estudos procuraram confirmar essa armadilha, mas os intervalos usados para investigá-la eram variados e amplos, indo de US\$2.000 a \$ 16.000 em PPP (Spence 2011; Felipe et al. 2012; Eichengreen et al. 2012). Intervalos tão grandes tornam a armadilha relativa. Por outro lado, as causas da estagnação geralmente associadas à armadilha são pouco convincentes. Está claro, porém, que a localização no tempo (anos 1980) está mais associada à estagnação econômica do que o nível da renda por habitante à relativa estagnação dos países latino-americanos.

A Tabela 1 compara a América Latina e o Leste da Ásia antes e depois da década de 1980. Ela confirma a quase estagnação da América Latina a partir dos anos 1980, e o crescimento rápido e continuado do Leste da Ásia. Por outro lado, o Gráfico 1 também demonstra que o Leste da Ásia e a América Latina cresciam a ritmos semelhantes até os anos 1980 e que, depois disso, a América Latina estagnou, enquanto o Leste da Ásia continuou a crescer rapidamente e países como a Coreia do Sul, Taiwan e Singapura já são países ricos.

Tabela 1: Taxas de Crescimento da América Latina e do Leste da Ásia antes e depois dos anos 1980

\begin{tabular}{|c|c|c|}
\hline & $1960-1980$ & $1991-2014$ \\
\hline América Latina & 3,0 & 1,2 \\
\hline Leste da Ásia & 4,7 & 5,3 \\
\hline
\end{tabular}

Fonte: PenWorld Tables - PWT, University of California. América Latina: Brasil, México, Argentina e Colômbia. Leste da Ásia: China, Coreia do Sul, Taiwan e Singapura (1954-60 não incluído).

As causas da armadilha da renda média apresentadas na literatura enfatizam a qualidade das instituições, aspectos demográficos, a carência de infraestrutura econômica, a má qualidade da educação, a ausência de estímulo ao aprendizado tecnológico e à pesquisa e desenvolvimento. Essas explicações, contudo, não representam fatos históricos novos que se manifestaram quando o país atingiu um determinado nível de renda. Esses problemas sempre existiram e, ainda assim, não impediram o crescimento até 1980.

Meu argumento é o de que o fato histórico novo que levou os países da América Latina à quase estagnação foram as reformas neoliberais adotadas por eles sob pressão dos Estados Unidos e do Banco Mundial, foram a liberalização comercial e 
a liberalização financeira da década de 1980. Em vez de falar em armadilha da renda média, devemos falar na "armadilha da liberalização comercial e financeira dos anos 1980". Os países deixaram de crescer rapidamente e de realizar o catching-up não por terem atingido um determinado nível de renda por pessoa, mas porque surgiu na década de 1980 um fato novo relevante. Pressionados pelo Ocidente, os países em desenvolvimento adotaram reformas neoliberais que implicaram desvantagem competitiva para suas empresas industriais e desindustrialização prematura.

Gráfico 1: Crescimento per capita da América Latina e do Leste da Ásia, 1960s-2014

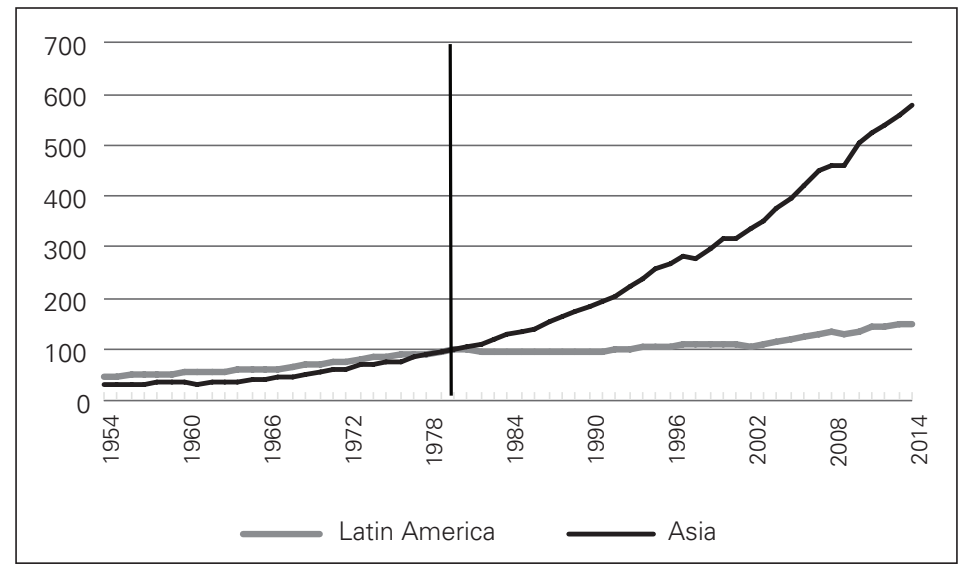

Fonte:

Obs.: América Latina: Brasil, México, Colômbia e Argentina.

É verdade que as duas regiões se dedicaram à liberalização comercial e financeira, mas os resultados negativos foram maiores nos países da América Latina do que na Ásia. Isto se deve ao fato de que nos países do Leste da Ásia tarifas aduaneiras foram necessárias apenas enquanto a indústria era infante, enquanto na América Latina elas continuaram necessárias depois que sua indústria deixou de ser nascente porque elas continuaram a ter como papel neutralizar a doença holandesa em relação ao mercado interno dos países. A teoria econômica convencional conhece apenas um argumento que torna as tarifas aduaneiras legítimas ao invés de meramente protecionistas: o argumento da indústria infante; com seu modelo de doença holandesa o Novo Desenvolvimentismo tornou legítimas as tarifas aduaneiras destinadas a neutralizar a desvantagem competitiva representada pela doença holandesa.

$\mathrm{O}$ argumento da indústria nascente legitima a proteção tarifária por um breve período, enquanto as tarifas adotadas para neutralizar a doença holandesa no mercado interno serão legítimas enquanto o país for exportador de commodities. A doença holandesa é uma sobreapreciação de longo prazo da taxa de câmbio em países que, por causa de rendas ricardianas ou devido a booms de preços, as empresas podem exportar com lucro commodities a uma taxa de câmbio significativamente mais apreciada do que aquela que empresas industriais que 
usem a melhor tecnologia disponível no mundo exigiriam para serem competitivas. Uma doença holandesa não neutralizada é um grande obstáculo à industrialização e ao crescimento.

Os países do Leste da Ásia não enfrentam o problema da doença holandesa. Assim, uma vez que o argumento da indústria nascente foi superado, eles abriram suas economias com sucesso como exportadores de bens manufaturados. Os países latino-americanos também superaram sua condição de indústria infante, mas como são exportadores de commodities as tarifas sobre importações continuam a ser necessárias para neutralizar a doença holandesa. Neste caso, as tarifas de importação sobre produtos industrializados não são protecionistas: apenas garantem às empresas de um determinado país condições iguais de competição.

A maneira correta de neutralizar a doença é impor um tributo variável sobre as exportações de commodities - variando de acordo com os preços internacionais dessas mercadorias. Mas esta é uma estratégia relativamente nova na literatura econômica, proposta originalmente por Bresser-Pereira (2008). Até hoje não tenho conhecimento de um país que tenha adotado esse método. Muitos estabelecem impostos sobre as exportações de commodities, mas eles têm objetivo apenas fiscal. Durante o período de industrialização acelerada (1950-1980), os responsáveis pelas políticas latino-americanas desconheciam a doença holandesa, mas aprenderam com a teoria desenvolvimentista clássica ou estruturalista que o crescimento é uma "mudança estrutural", ou seja, implica industrialização. Por isso, adotavam pragmaticamente qualquer política que levasse à industrialização. A política mais óbvia visando esse objetivo foi a do estabelecimento de tarifas elevadas sobre a importação de manufaturados, que neutralizavam a doença holandesa em relação ao mercado interno; com menos frequência, adotaram subsídios às exportações que fazem essa neutralização em relação aos mercados externos. O Brasil foi um desses países. Em 1967, quando as exportações de manufaturados representavam apenas $6 \%$ do total de suas exportações, adotou um elevado subsídio à exportação. O resultado foi notável. Em 1990, essa porcentagem havia subido para $62 \%$. Muitos países adotaram também sistemas de câmbio múltiplo, que, igualmente, neutralizavam a doença holandesa ainda que os formadores de políticas econômicas não tivessem claro para eles o problema que enfrentavam.

A doença holandesa é uma grande desvantagem competitiva, embora seja difícil determinar quão grande. Isso depende essencialmente da sua severidade e da sua variação nos ciclos de boom de commodities e nos correspondentes ciclos de taxa de câmbio. A gravidade da doença holandesa é igual à diferença percentual entre o equilíbrio industrial (a taxa de câmbio de que empresas industriais competentes necessitam) e o equilíbrio corrente (a taxa de câmbio que equilibra intertemporalmente a conta-corrente do país). Por exemplo, se o equilíbrio industrial de um país for $\mathrm{R} \$ 4,00$ por dólar americano e o equilíbrio corrente for $\mathrm{R} \$ 3,30$ por dólar, a doença holandesa será de $\$ 0,70$ por dólar e sua gravidade será $17,5 \%$.

O petróleo é a principal origem da doença holandesa e, mantido constante seu preço internacional (refletindo o custo marginal do exportador menos eficiente admitido ao mercado), sua gravidade dependerá do custo de produção do petróleo. 
Por exemplo, a doença holandesa e muito grave na Arábia Saudita, que enfrenta a doença desde que se tornou um país exportador de petróleo. Em outros países - o Brasil, por exemplo - cuja desvantagem competitiva tenha se originado de café, carne ou soja, a doença holandesa é menos grave e pode até mesmo desaparecer quando caem os preços dessas mercadorias.

Assim, quando o Ocidente pressionou pela liberalização comercial à América Latina nos anos 1980 (com a anuência das elites dependentes locais), os países do Leste da Ásia também abriram suas economias, mas já estavam antes relativamente abertos porque não tinham doença holandesa e já eram exportadores de bens manufaturados para isso porque o argumento da indústria nascente perdera a validade e eles puderam contar com um setor industrial competitivo. Muito diferente foi o caso das empresas industriais competentes da América Latina. Com a abertura comercial a doença holandesa deixou de ser neutralizada e essas empresas passaram imediatamente a enfrentar uma grande desvantagem competitiva.

A armadilha da liberalização dos anos 1980 também atingiu os países latino-americanos pelo lado financeiro porque, com ela, os países perderem o relativo controle que tinham sobre sua taxa de câmbio. Na maioria dos casos essa taxa era corrigida pela inflação através de um sistema de minidesvalorizações (sistema de crawling peg). Com a abertura financeira acoplada a uma política de juros altos para atrair capitais (uma política que o Novo Desenvolvimentismo critica porque esses capitais apreciam a taxa de câmbio, estimulam o consumo e desestimulam o investimento), as taxas de câmbio na América Latina se apreciaram e as boas empresas perderam competitividade.

Desde 1980, a China apenas apresentou déficits em conta-corrente em três anos. A Coreia do Sul só usou o endividamento externo na década de 1970, quanto crescia muito rapidamente, e, por isso, a taxa de substituição de poupança interna por externa foi baixa. Enquanto isso os países latino-americanos, crendo equivocadamente poder crescer com poupança externa, apresentam regularmente déficits em conta-corrente que inviabilizam suas empresas industriais.

Esta política é equivocada e costuma estar associada a uma elevada taxa de substituição de poupança interna por externa. Foi equivocada não só porque o país corre o risco de passar por crises financeiras cíclicas. Mesmo que o país procure limitar seu endividamento externo para evitar o crescimento de suas taxas de dívida externa (em relação ao PIB e às exportações) e as crises cambiais delas decorrentes, a política ainda assim será equivocada porque irá continuar a desestimular o investimento e estimular o consumo. É só sob condições excepcionais, enquanto um país experimentar crescimento muito rápido, que esse resultado será evitado porque as maiores oportunidades de lucro reduzirão a propensão marginal ao consumo.

Rejeitar a ideia de que países pobres em capital devam receber capital de países ricos em capital é contraintuitiva, mas fácil de explicar. Um déficit em conta-corrente corresponde a uma moeda mais apreciada do que uma conta corrente equilibrada. Déficits em conta-corrente e o respectivo financiamento externo significam um aumento adicional e constante dos influxos de capital de um país, o 
que irá necessariamente apreciar sua moeda enquanto permanecer o déficit. No modelo novo-desenvolvimentista, uma moeda apreciada no longo prazo desestimula o investimento e o crescimento. Assim, dada a apreciação da moeda, a moeda estrangeira financiará o aumento do consumo e não o do investimento. O poder aquisitivo dos salários e as rendas dos capitalistas rentistas aumentarão, enquanto os investimentos do setor privado fenecerão porque a apreciação da moeda nacional no longo prazo desconecta as empresas industriais competentes não só da demanda externa, mas também da interna. A liberalização financeira entra em cena porque, para implantar uma política de crescimento com poupança externa, o país precisa aumentar suas taxas de juros de maneira a atrair capital, e deixar inteiramente livres seus influxos.

Em suma, enquanto os países do Leste da Ásia foram pouco atingidos pela liberalização adicional dos anos 1980 e continuaram a crescer, a liberalização atingiu duramente os países latino-americanos, devido a algumas razões interligadas: porque, com a liberalização comercial e financeira, houve na América Latina o desmantelamento do mecanismo de neutralização da doença holandesa e este fato mais a elevação dos juros implicou apreciação das moedas nacionais e, portanto, suas empresas passaram a enfrentar uma desvantagem competitiva de longo prazo, ao passo que as do Leste da Ásia competem em igualdade de condições com os países industrializados.

\section{REFERÊNCIAS BIBLIOGRÁFICAS}

Bresser-Pereira, Luiz Carlos. (2008). "The Dutch Disease and its neutralization: A Ricardian approach”. Revista de Economia Politica 28(1):47-71. Doi: 10.1590/S0101-31572008000100003.

Bresser-Pereira, Luiz Carlos. (2016). "Reflecting on New Developmentalism and Classical Developmentalism". Review of Keynesian Economics 4(3):331-52. doi: 10.4337/roke.2016.03.07.

Bresser-Pereira, Luiz Carlos, José Luis Oreiro, e Nelson Marconi. (2016). Macroeconomia Desenvolvimentista. Rio de Janeiro: Elsevier.

Eichengreen, Barry, Donghyun Park e Kwanho Shin. (2012). "When fast growing economies slow down: international evidence and implications for China". Asian Economic Papers 11(1):42-87.

Felipe, Jesus, Abdon Amelyn e Utsav Kumar. (2012). "Tracking the middle income trap: what is it, who is in it, and why?”. Working Paper no. 715, Levy Economics Institute, Abril. http://www.levyinstitute.org/pubs/wp_715.pdf.

Spence, Michael. (2011). The Next Convergence. The Future of Economic Growth in a Multispeed World. Nova York: Farrar, Straus, and Giroux. 